\title{
Solvent free synthesis and structural evaluation of polyurethane films based on poly(ethylene glycol) and poly(caprolactone)
}

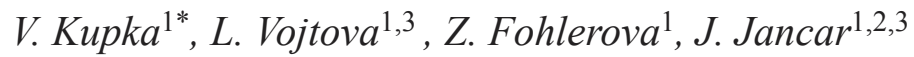 \\ ${ }^{1}$ CEITEC - Central European Institute of Technology, Brno University of Technology, Technicka 3058/10, 616 00 Brno, \\ Czech Republic \\ ${ }^{2}$ Institute of Materials Chemistry, Faculty of Chemistry, Brno University of Technology, Purkynova 118, 61200 Brno, \\ Czech Republic \\ ${ }^{3}$ SCITEG a.s., Brno, Czech Republic
}

Received 31 October 2015; accepted in revised form 4 January 2016

\begin{abstract}
Biodegradable amphiphilic polyurethane films (bio-PUs) were synthesized by solvent free polyaddition reaction of hydrophilic poly(ethylene glycol) (PEG) and hydrophobic poly(caprolactone) (PCL) as macrodiols with hexamethylene diisocyanate. Samples were subsequently heat cured in order to obtain 3D crosslinked structure. Different PCL/PEG ratios allowed controlling the toughness of the resulting bio-PUs. Significant enhancement of Young's modulus, strength and elongation at break was observed at a PCL/PEG molar ratio above 3. The change in the bio-PU mechanical behavior was ascribed to the formation of crystalline PCL domains in the bio-PU network. The presence of PEG increased both the ability to absorb water and the rate of hydrolytic degradation, while PCL increased the cell viability. Prepared solvent free bio-PUs may advantageously be used in medicine as elastic resorbable material applicable against post-surgical adhesions.
\end{abstract}

Keywords: biodegradable polymers, polyurethane, elastomer, poly(ethylene glycol), poly(caprolactone)

\section{Introduction}

Polyurethanes (PUs) form diverse class of elastomers covering a broad range of chemical and physical properties. In addition to industrial applications, their structure can be also formed from bioresorbable materials for the use in human medicine [1-4]. Favorable parameters of PUs for the use particularly in tissue engineering are tissue-specific biocompatibility, biodegradability, mechanical flexibility and moderate blood compatibility. PUs were initially used in medicine as bio-inert, hydrolytically stable materials (e.g. ventricle assist devices or heart valves [5]). Later on, bioresorbable PUs were introduced for various tissue constructs such as vascular grafts [6], car- tilage [7], cancellous bone graft substitutes [8] or as grafts for small diameter vascular replacement [9]. Moreover, bioresorbable PUs can be tailored to possess a broad range of mechanical properties by selections and content of soft and hard segments $[10,11]$. Soft segments are commonly polyols represented by polyesters such as poly(E-caprolactone) (PCL), poly (lactic acid) and poly(glycolic acid) or polyethers like poly(ethylene glycol) (PEG) and poly(propylene glycol) having a low glass transition temperature (lower than $25^{\circ} \mathrm{C}$ ). The hard segments are provided by the combination of the chain extender and the diisocyanate component. The nature of hydrogen bonding in the hard segment causes a mutual

\footnotetext{
*Corresponding author, e-mail: vojtech.kupka@ceitec.vutbr.cz (C) BME-PT
} 
attraction leading to a formation of hard and soft segment domains [12]. To eliminate the concern of aromatic amine by-products, the utilization of aliphatic diisocyanates (as alternatives to aromatic ones) provide a route to synthetize biodegradable polyurethanes yielding non-toxic degradation products [3]. Generally, PUs are synthesized either by polymerization in a solvent or in bulk. Subsequently, processing of PU polymers into films is carried out by dissolving the polymer in a solvent such as dimethyl sulfoxide (DMSO) or dimethylformamide (DMF) followed by casting into a mold. A range of bioresorbable linear PU systems has already been described in the literature [13-20]. However, avoiding the use of organic solvent is a favorable parameter for a material with the potential use in medicine.

In this work, we present novel and original solvent free 'green chemistry' procedure yielding compact biodegradable cross-linked PCL/PEG bio-PU films eliminating organic solvents commonly used in PU synthesis. Polymerization conditions were optimized and the effect of PCL/PEG ratio on the prepared bioPU structure and physical properties is discussed below.

\section{Experimental}

\subsection{Chemicals}

Poly ( $\varepsilon$-caprolactone) diol (PCL, $M_{\mathrm{n}}=530 \mathrm{~g} \cdot \mathrm{mol}^{-1}$, Sigma-Aldrich, Germany) and poly(ethylene glycol) (PEG, $M_{\mathrm{n}}=400 \mathrm{~g} \cdot \mathrm{mol}^{-1}$, Sigma-Aldrich, Germany) were degassed at $130^{\circ} \mathrm{C}$ for 3 hours before the synthesis; 1,6-diisocyanatohexane (HDI, 98\%, SigmaAldrich, Germany) was degassed at the laboratory temperature for 3 hours. Tin(II) 2-ethylhexanoate (95\%, Sigma-Aldrich, Germany) and gaseous nitro- gen (99.999 \%, SIAD Czech spol. s r.o.) were used as received. Dealing with wide-angle X-ray scattering (WAXS) measurements high molecular weight poly( $\varepsilon$-caprolactone) (PCL, $M_{\mathrm{n}}=80000 \mathrm{~g} \cdot \mathrm{mol}^{-1}$, Sigma-Aldrich, Germany) was used due to its high crystallinity. Ultrapure water (UPW) of type II according to ISO 3696 was prepared on Elix 5 UV Water Purification System (Merck Millipore).

\subsection{Synthesis}

Synthesis was carried out under nitrogen atmosphere using a high vacuum manifold utilizing Schlenk's technique in combination with nitrogen flushed glove-box. Typical synthesis procedure is described below.

PCL and PEG were used as macrodiol components either alone or in the mixture under given PCL/PEG molar ratio. Both PEG and PCL were chosen with the low number average molecular weight $\left(M_{\mathrm{n}}=\right.$ $400 \mathrm{~g} \cdot \mathrm{mol}^{-1}$ and $M_{\mathrm{n}}=530 \mathrm{~g} \cdot \mathrm{mol}^{-1}$, respectively), to allow easy casting of the reaction mixture into the mold at laboratory temperature. Firstly, degassed macrodiols were mixed together at the laboratory temperature for 1 hour. Consequently, $0.03 \mathrm{~mol} \%$ of tin(II) 2-ethylhexanoate catalyst (related to moles of -OH groups in the mixture) was added followed by vigorous stirring for 1 hour to maximize dispersion of the catalyst. Finally, HDI in the molar ratio of $\mathrm{NCO} / \mathrm{OH}=1.2$ was dosed into the diol mixture in glove-box, stirred at $250 \mathrm{rpm}$ and the viscous polymer was poured into the $1 \mathrm{~mm}$ thick top-covered teflon ${ }^{\circledR}$ mold. The sample was left to cure overnight in the mold at room temperature followed by post-curing in the oven for 24 hours at $65^{\circ} \mathrm{C}$. Seven series of bio-PUs was prepared with varying

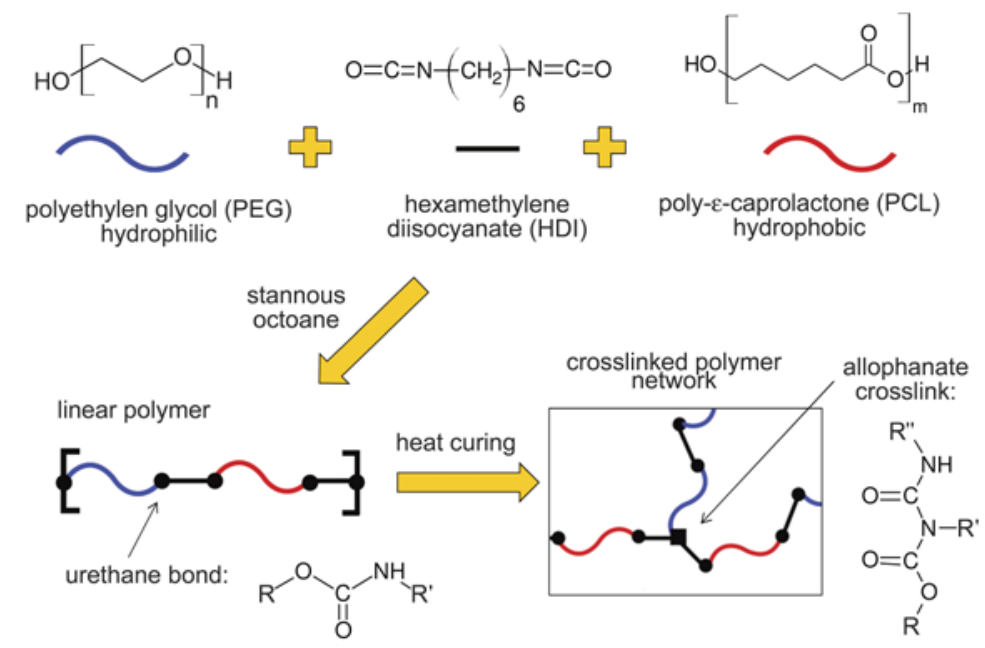

Figure 1. Procedure scheme for preparation of bio-PU films 
Table 1. Composition of the prepared PU samples differing in the amount of PCL and PEG

\begin{tabular}{|l|c|c|c|c|}
\hline $\begin{array}{c}\text { PU sample } \\
\text { label }\end{array}$ & $\begin{array}{c}\text { Molar } \\
\text { ratio of } \\
\text { PCL/PEG }\end{array}$ & $\begin{array}{c}\text { Weight } \\
\text { ratio of } \\
\text { PCL/PEG }\end{array}$ & $\begin{array}{c}\text { NCO/OH } \\
\text { ratio }\end{array}$ & Turbidity \\
\hline $\mathrm{PU}_{\mathrm{PEG}}$ & $0 / 100$ & $0 / 100$ & 1.2 & Transparent \\
\hline $\mathrm{PU}_{0.3}$ & $24 / 76$ & $30 / 70$ & 1.2 & Transparent \\
\hline $\mathrm{PU}_{0.8}$ & $43 / 57$ & $50 / 50$ & 1.2 & Transparent \\
\hline $\mathrm{PU}_{1.8}$ & $64 / 36$ & $70 / 30$ & 1.2 & Transparent \\
\hline $\mathrm{PU}_{3.0}$ & $75 / 25$ & $80 / 20$ & 1.2 & Translucent \\
\hline $\mathrm{PU}_{6.7}$ & $87 / 13$ & $90 / 10$ & 1.2 & Translucent \\
\hline $\mathrm{PU}_{\mathrm{PCL}}$ & $100 / 0$ & $100 / 0$ & 1.2 & Translucent \\
\hline
\end{tabular}

PCL/PEG molar ratio. The scheme of the procedure is sketched in Figure 1. The composition of the prepared samples is summarized in Table 1.

\subsection{Characterization methods}

\subsubsection{Temperature profiles acquisition}

Temperature profiles were acquired by thermocouple inserted into the reaction mixture. The synthesis procedure was performed similarly to the described one in chapter 2.2. Instead of pouring the reacting mixture into the mold, the mixture was let to react until the obvious temperature decrease was recognized. Profiles were depicted for $\mathrm{PU}_{\mathrm{PEG}}$ and $\mathrm{PU} \mathrm{PCL}_{\mathrm{PC}}$ samples. Each profile was measured twice to confirm the acquired trend. Reported results are depicted from the first measurement.

\subsubsection{Ultraviolet-visible spectroscopy (UV-VIS)}

Absorbance spectra were obtained using UV-VIS spectrophotometer (Jasco V-630, USA) in the interval of wavelengths from 240 to $1100 \mathrm{~nm}$ with resolution of $0.5 \mathrm{~nm}$. Films with a thickness of $1.0 \pm 0.1 \mathrm{~mm}$ were placed directly into the light path and measured.

\subsubsection{Attenuated total reflection infrared spectroscopy (ATR-IR)}

Attenuated total reflection infrared spectroscopy (ATR-IR) was performed on Fourier-transform infrared spectrometer (Bruker Tensor 27, USA) equipped with a germanium crystal for ATR over the spectral range from 4000 to $600 \mathrm{~cm}^{-1}$ at the resolution of $4 \mathrm{~cm}^{-1}$ and 32 scans.

\subsubsection{Wide-angle $X$-ray scattering}

Wide-angle X-ray scattering (WAXS) was performed on the diffractometer (Rigaku MiniFlex 600, Japan) with $\mathrm{Cu} \mathrm{K}$ radiation $(\lambda=1.5406 \AA)$ operated at
$40 \mathrm{kV}$ and $15 \mathrm{~mA}$ and the scattering angle (20) ranging from 5 to $35^{\circ}$ with the scan rate of $2^{\circ} \cdot \mathrm{min}^{-1}$ with step of $0.02^{\circ}$. For calculating the size of crystallites according to Scherrer equation, the baseline was set as a line anchored to corresponding spectra from 15 to $30^{\circ}$. As a reference material, WAXS of a commercial PCL $\left(M_{\mathrm{n}}=80000 \mathrm{~g} \cdot \mathrm{mol}^{-1}\right)$ with high crystallinity was also measured.

\subsubsection{Differential scanning calorimetry (DSC)}

Calorimetric measurements were carried out utilizing differential scanning calorimetry (DSC) (Netzsch 204 F1, Germany) in nitrogen atmosphere. Each sample $(5-10 \mathrm{mg})$ was heated first from -80 up to $100^{\circ} \mathrm{C}$ with heating rate of $10^{\circ} \mathrm{C} \cdot \mathrm{min}^{-1}$. Raw data were processed using the NETZSCH Proteus ${ }^{\circledR}$ Software to obtain glass transition temperature $\left(T_{\mathrm{g}}\right)$, melting temperature $\left(T_{\mathrm{m}}\right)$ and melting enthalpy $\left(\Delta H_{\mathrm{m}}\right)$. The crystallinity $\left(\alpha_{\mathrm{c}}\right)$ was calculated from the first DSC heating run according to Equation (1):

$\alpha_{\mathrm{c}}[\%]=\frac{\Delta H_{\mathrm{m}} \cdot 100}{w \cdot \Delta H_{\mathrm{m}}^{0}}$

where $\Delta H_{\mathrm{m}}$ is heat of fusion of the bio-PU sample, $\Delta H_{\mathrm{m}}^{0}$ is heat of fusion of $100 \%$ crystalline PCL $\left(135.44 \mathrm{~J} \cdot \mathrm{g}^{-1}\right)$ [21] and $w$ is the PCL's weight fraction in the bio-PU sample.

\subsubsection{Thermogravimetric analysis (TGA)}

Thermal decompositions of bio-PUs were investigated using the thermogravimetric analysis (TGA) (TA Q500, USA) with sample mass in the range between $5-10 \mathrm{mg}$. All measurements were carried out in nitrogen atmosphere with a flow rate of $100 \mathrm{~mL} \cdot \mathrm{min}^{-1}$. Heating rate was set at $10^{\circ} \mathrm{C} \cdot \mathrm{min}^{-1}$ starting from 25 up to $750^{\circ} \mathrm{C}$.

\subsubsection{Swelling}

Swelling ratio of $10 \times 10 \times 1 \mathrm{~mm}$ specimens was measured in Ultrapure water (UPW) at laboratory temperature. Sample weight was measured every ten minutes within the first hour, every 20 minutes within the second hour and then every hour for the next 4 hours with the last measurement performed after 1 day since the beginning of the swelling experiment. Water uptake was calculated according to the Equation (2):

Water uptake $[\%]=\frac{w_{\mathrm{s}}-w_{\mathrm{d}}}{w_{\mathrm{d}}} \cdot 100$ 
where $w_{\mathrm{s}}$ is the weight of swollen sample at the given time and $w_{\mathrm{d}}$ is the weight of dry sample. From every sample three pieces were measured at each time point and data were expressed as mean \pm standard deviation.

\subsubsection{Hydrolytic degradation}

Hydrolytic degradation tests employing the swelled samples were carried out in an incubator at $37^{\circ} \mathrm{C}$ in UPW for 365 days. Each measurement was an average of 3 specimens and data were expressed as mean \pm standard deviation. The specimens were removed at the given time from vials with UPW, wiped using filter paper and weighed to determine the weight loss. The UPW was changed every two weeks. Mass loss was calculated according to Equation (3):

Mass loss $[\%]=\frac{w_{0}-w_{\mathrm{t}}}{w_{0}} \cdot 100$

where $w_{0}$ is the weight of swollen sample after 24 hours in water and $w_{\mathrm{t}}$ is the weight of the sample at the given time.

\subsubsection{Extraction}

Extraction of the bio-PU films was performed using Soxhlet apparatus. Small $10 \times 10 \times 1 \mathrm{~mm}$ pieces of dry bio-PU films were used for the extraction in dimethylformamide (DMF) and in acetone. Extractions were performed for 8 hours in $200 \mathrm{~mL}$ of the solvent followed by drying extracted samples in the vacuum oven at $25^{\circ} \mathrm{C}$ to the constant weight. Weight loss was calculated according to Equation (4):

Weight loss $[\%]=\frac{w_{0}-w_{\mathrm{e}}}{w_{0}} \cdot 100$

where $w_{0}$ is the weight of the sample before extraction and $w_{\mathrm{e}}$ is the weight of the sample after extraction. Extracts obtained from acetone with bio-PU dissolved residues were thickened by acetone evaporation and dried in the vacuum oven to be ATR-IR analyzed.

\subsubsection{Tensile measurement}

Tensile tests were performed employing a tensile tester (Zwick Roell Z010, Germany) according to the ISO 527 standard. Dog-bone specimens obtained according to ISO $527-2 / 5 \mathrm{~B}$ were $35 \mathrm{~mm}$ in length, $2 \mathrm{~mm}$ in width in the middle part, $1 \mathrm{~mm}$ thick and gauge length was $10 \mathrm{~mm}$. A $500 \mathrm{~N}$ load cell was used for the measurements with a cross-head speed of $10 \mathrm{~mm} \cdot \mathrm{min}^{-1}$ corresponding to a $100 \% \cdot \mathrm{min}^{-1}$ deformation rate. The $0.1 \mathrm{~N}$ preload was used and all tensile measurements were performed at the laboratory temperature. Six dog-bones were measured from each sample and data were averaged to get the standard deviation.

\subsubsection{Confocal laser scanning microscopy (CLSM)}

Morphology of the bio-PU films was acquired by confocal laser scanning microscope (Olympus OLS 3000 LEXT). Roughness average $\left(R_{\mathrm{a}}\right)$ was evaluated using the Olympus software. Five profiles were acquired from each sample and data were expressed as mean \pm standard deviation. The length of the profile line for the $R_{\mathrm{a}}$ parameter calculation was $126 \mu \mathrm{m}$.

\subsubsection{Contact angle measurement}

Contact angle measurements were carried out on films using a contact angle apparatus (OCA 10, Dataphysics, Germany). The used liquid probe was ultrapure water. Drop of $1 \mu \mathrm{L}$ was deposited on a bioPU film and contact angle was acquired when steady state for angle was reached (around $t=10 \mathrm{~s}$ ). Measurement was repeated five times on each film and data were expressed as mean \pm standard deviation.

\subsubsection{Cell viability evaluation}

Selected samples of $\mathrm{PU}_{\mathrm{PEG}}, \mathrm{PU}_{3.0}$ and $\mathrm{PU}_{\mathrm{PCL}}$ films were tested for cytotoxicity by seeding human mesenchymal stem cells (MSCs) and evaluating their adhesion and viability after 24, 72 and 168 hours. Human MSCs were isolated from a fatty tissue of three healthy donors who had undergone cosmetic liposuction. Isolation of MSCs was based on the incubation of fresh lipoaspirates with collagenase and expanded in complete Dulbecco's Modified Eagle's medium with low glucose. Bio-PU $1 \mathrm{~mm}$ thick films in the form of $6 \mathrm{~mm}$ discs were sterilized using a combination of UV (15 min) and ethanol followed by incubation in culture medium (Dulbecco's Modified Eagle's medium with L-glutamine, 10\% fetal bovine serum, $1 \%$ penicillin/streptomycin) overnight at $37^{\circ} \mathrm{C}$. Cells were seeded on the films at a density of $3 \cdot 10^{4}$ cells $\cdot \mathrm{cm}-2$ in 48 -well plate. Bio-PU films with seeded MSCs were cultivated at $37^{\circ} \mathrm{C}$ and $5 \% \mathrm{CO}_{2}$ atmosphere. The medium was changed every 3 days. Fluorescence microscopy and live/ dead staining (calcein-AM/propidium iodide) were 
used to determine cell viability acquired in 24,72 and 168 hours after seeding. The mix of calcein-AM $(2 \mu \mathrm{M})$ and propidium $(1,5 \mu \mathrm{M})$ in phosphate buffered saline (PBS) was added to the cell-seeded films and incubated for $15 \mathrm{~min}$ at $37^{\circ} \mathrm{C}$ and $5 \%$ $\mathrm{CO}_{2}$ for live/dead cell detection. The cells were visualized using a Zeiss Axio Imager 2 microscope.

\section{Results and discussion}

Seven bio-PU samples with different PCL/PEG ratios were prepared in order to obtain biodegradable films applicable in regenerative medicine. Liquid low-molecular weight diols (hydrophilic PEG $\left(M_{\mathrm{n}}=400 \mathrm{~g} \cdot \mathrm{mol}^{-1}\right)$ and hydrophobic PCL $\left(M_{\mathrm{n}}=\right.$ $530 \mathrm{~g} \cdot \mathrm{mol}^{-1}$ ) were used for polyaddition reaction with HDI without the use of any organic solvent. Important feature of the procedure was finding a proper time for pouring the reacting polymer into a mold. The mixing time was set according to acquired temperature profiles depicted in Figure 2. Rapid temperature's increase in the mixture of PEG with

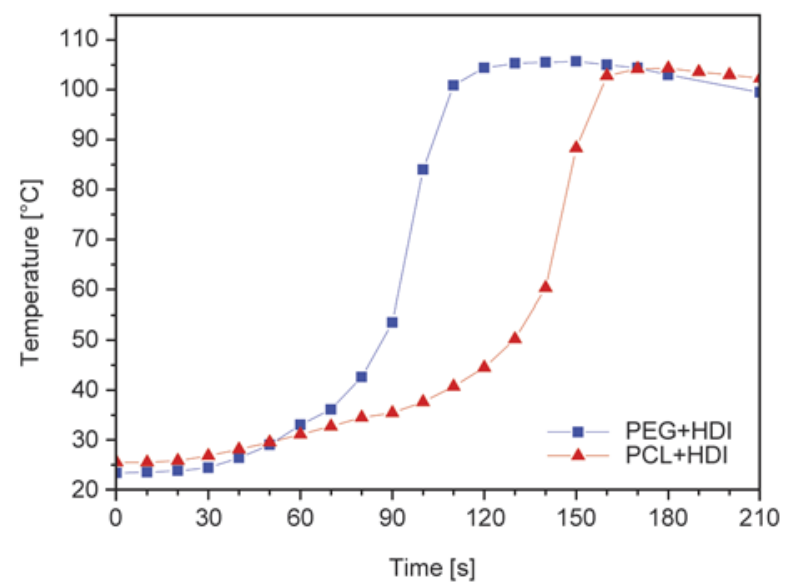

Figure 2. Temperature profiles of reaction between PEG with HDI and PCL with HDI
HDI or PCL with HDI after 90 and $140 \mathrm{sec}$, respectively, was accompanied by increase in viscosity. In order to easily pour the reacting mixture into the mold the time of mixing was set at $80 \mathrm{sec}$ for all the samples.

\subsection{Structural analysis}

Captured images of samples in Figure 3 are showing differences in opacity. Bio-PU films having ratio $\mathrm{PCL} / \mathrm{PEG}$ equal to 1.8 and lower were transparent (Figure 3a), when the molar excess of PCL was equal to 3 or higher bio-PU films became semitransparent (Figure 3b) and samples with higher PCL's content were opaque (Figure 3c). This phenomenon was confirmed by UV-VIS measurements (see Figure 4) showing that bio-PU films having ratio $\mathrm{PCL} / \mathrm{PEG}$ equal to 1.8 and lower were without significant absorption in the visible spectra from 390 to $700 \mathrm{~nm}$. However, when the molar excess of

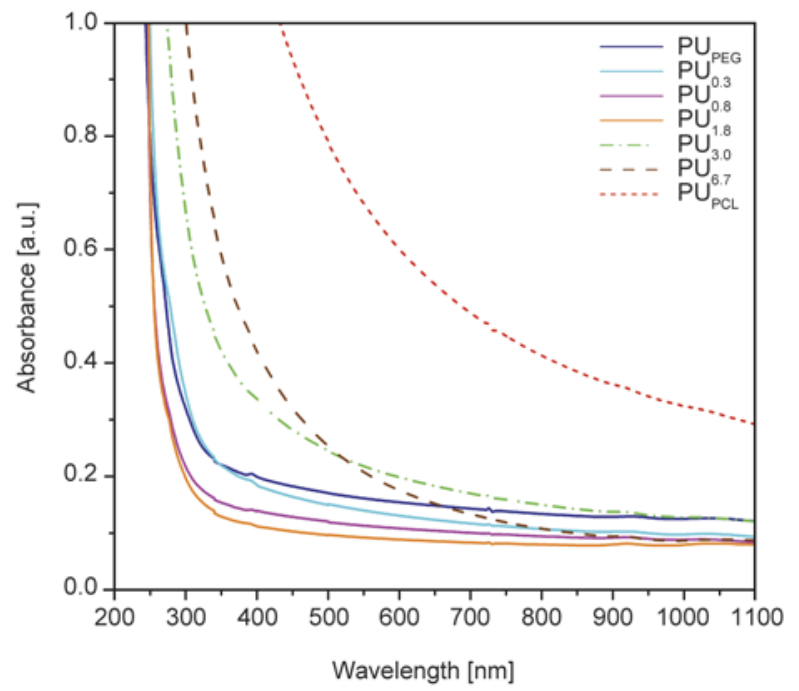

Figure 4. UV-VIS spectra showing change in opacity of bio-PUs

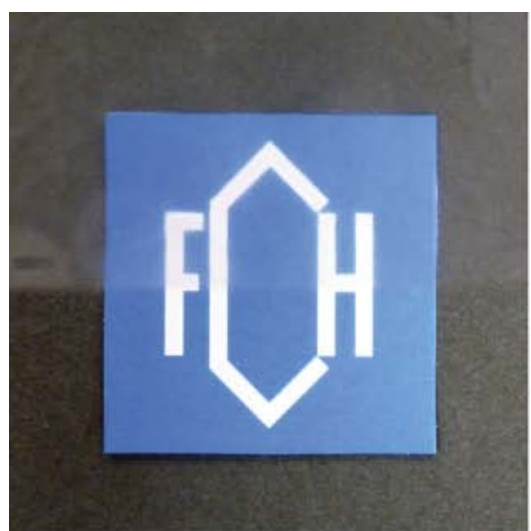

a)



b)

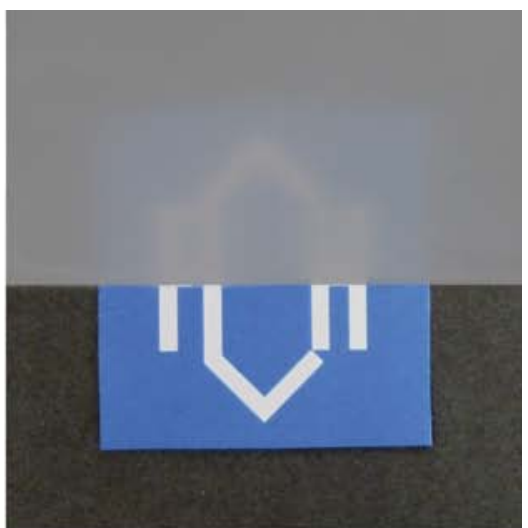

c)

Figure 3. Images of samples differing in opacity: a) transparent $\mathrm{PU}_{\mathrm{PEG}}$ sample, b) semi-transparent $\mathrm{PU}_{3.0}$ and c) opaque $\mathrm{PU} \mathrm{PCL}_{\mathrm{P}}$ 
PCL was equal to 3 or higher, absorbance increased in the visible spectra range in agreement with semitransparent appearance of $\mathrm{PU}_{3.0}$ sample. The highest absorbance exhibited sample $\mathrm{PU}_{\mathrm{PCL}}$ with opaque inhomogeneities.

The chemical structure of the synthesized bio-PU samples was qualitatively evaluated using ATR-IR spectroscopy. First, the spectra of $\mathrm{PU}_{\mathrm{PEG}}$ and $\mathrm{PU} \mathrm{UCL}_{\mathrm{PCL}}$ were compared with spectra of neat PEG, PCL and HDI (Figure 5) confirming the formation of urethane bonds. Their characteristic bands are represented by $\mathrm{N}-\mathrm{H}$ stretching vibration at 3335 and at $3321 \mathrm{~cm}^{-1}$ for $\mathrm{PU}_{\mathrm{PEG}}$ and $\mathrm{PU}_{\mathrm{PCL}}$, respectively. The absorption of amide II (urethane $\mathrm{N}-\mathrm{H}$ bending and $\mathrm{C}-\mathrm{N}$ stretching) is located at $1536 \mathrm{~cm}^{-1}$. Strong absorption of $\mathrm{C}=\mathrm{O}$ band is located at $1714 \mathrm{~cm}^{-1}$ and, in the case of $\mathrm{PU}_{\mathrm{PEG}}$, it was assigned to hydrogen bonded carbonyl groups in the disordered conformations [22]. In the case of $\mathrm{PU} \mathrm{PCL}_{\mathrm{PL}}$ the $\mathrm{C}=\mathrm{O}$ peak split into two peaks, where the first one at $1730 \mathrm{~cm}^{-1}$ belongs to nonhydrogen bonded ester carbonyl groups and the second one at $1683 \mathrm{~cm}^{-1}$ was ascribed to hydrogen bonded carbonyl in crystalline region [23].

Other peaks presented in the spectra were assigned to asymmetric and symmetric $\mathrm{CH}_{2}$ stretching located at 2919 and $2866 \mathrm{~cm}^{-1}$ for PU $\mathrm{PEG}_{\text {and }}$ at 2935 and $2858 \mathrm{~cm}^{-1}$ for the $\mathrm{PU}_{\text {PCL. Other }} \mathrm{CH}_{2}$ vibrations are demonstrated by the bands at 1458 and

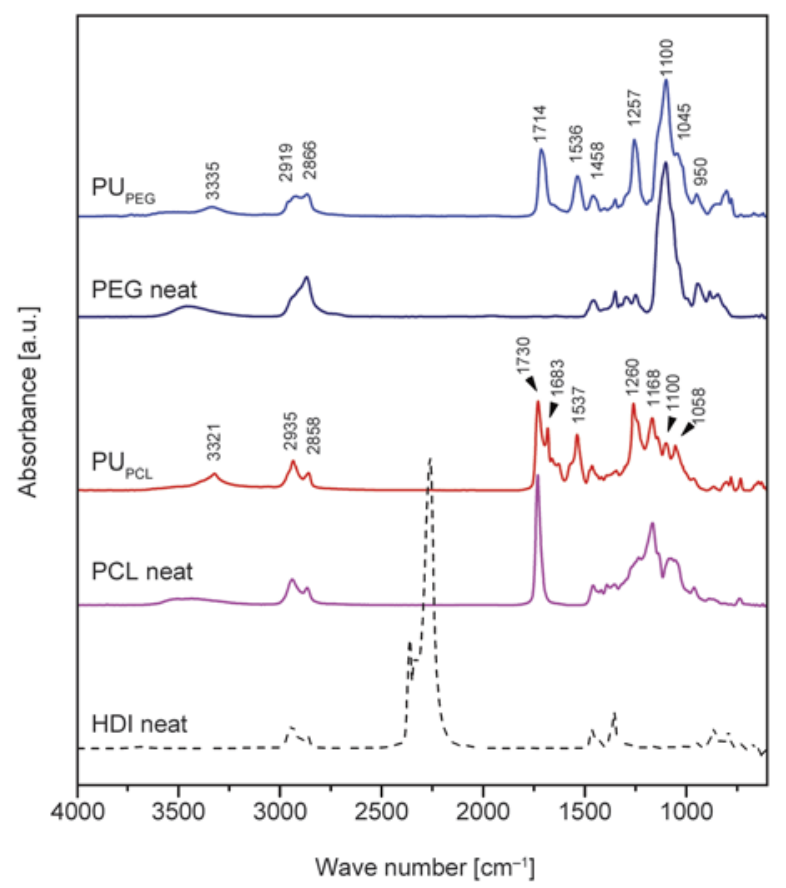

Figure 5. ATR-IR spectra of $P U_{P E G}$ (blue line), $P E G$ neat (dark blue line), $\mathrm{PU}_{\mathrm{PCL}}$ (red line), PCL neat (violet line) and HDI neat (black dashed line)
$1350 \mathrm{~cm}^{-1}$ for the PUPEG sample and 1464, 1344 and $1260 \mathrm{~cm}^{-1}$ for PUPCL sample. The band at $1100 \mathrm{~cm}^{-1}$ in the PU $U_{\mathrm{PEG}}$ sample was attributed to stretching vibration of ether $\mathrm{C}-\mathrm{O}-\mathrm{C}$ bond in the PEG chain and in the $\mathrm{PU}_{\mathrm{PCL}}$ sample was assigned to $\mathrm{C}-\mathrm{O}-\mathrm{C}$ ester bond. The strong isocyanate bands at 2360 and $2270 \mathrm{~cm}^{-1}$ are absent in both PU $\mathrm{PEG}_{\text {and }}$ $\mathrm{PU}_{\mathrm{PCL}}$ spectra indicating complete conversion of the HDI during synthesis.

Interesting differences were observed when comparing free and hydrogen bonded carbonyl groups in all prepared bio-PUs as illustrated in Figure 6. The $\mathrm{PU}_{\mathrm{PEG}}$ and the bio-PUs with PCL/PEG ratio below $1.8\left(\mathrm{PU}_{0.3}, \mathrm{PU}_{0.8}\right.$ and $\left.\mathrm{PU}_{1.8}\right)$ showed carbonyl peak in the region ascribed to hydrogen bonded $\mathrm{C}=\mathrm{O}$ groups in disordered (amorphous) region [22]. However, the bio-PUs having the $\mathrm{PCL} / \mathrm{PEG}$ ratio higher than $3\left(\mathrm{PU}_{3.0}, \mathrm{PU}_{6.7}\right.$ and $\left.\mathrm{PU}_{\mathrm{PCL}}\right)$ exhibited $\mathrm{C}=\mathrm{O}$ stretching at $1730 \mathrm{~cm}^{-1}$ assigned to non-hydrogen bonded ester carbonyl and also in the region between $1690-1674 \mathrm{~cm}^{-1}$ ascribed to hydrogen bonded carbonyl groups in ordered (crystalline) region. The possible functional groups acting as electron donors in the hydrogen bonding with the amide group are the urethane and the ester carbonyl. The higher amount of hydrogen bonded $\mathrm{C}=\mathrm{O}$ groups in the PCL rich compositions can be explained by the PCL domain crystallinity. The parallel chains orientation in the crystalline regions is assumed to promote the formation of hydrogen bonds.

The glass transition temperature $\left(T_{\mathrm{g}}\right)$, melting temperatures $\left(T_{\mathrm{m}}\right)$, and crystallinity were determined using DSC traces (Table 2). DSC traces obtained

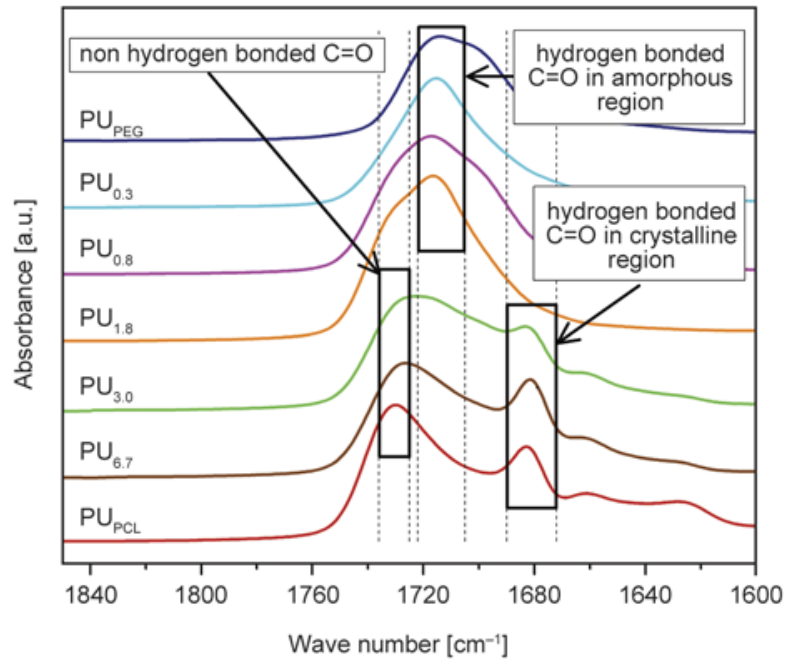

Figure 6. ATR-IR absorption spectra of bio-PU samples showing $\mathrm{C}=\mathrm{O}$ stretching region 
Table 2. $T_{\mathrm{g}}, T_{\mathrm{m}}$ and crystallinity of bio-PU films obtained from DSC thermographs

\begin{tabular}{|l|c|c|c|}
\hline Sample label & $\begin{array}{c}\boldsymbol{T}_{\mathbf{g}} \\
{\left[{ }^{\circ} \mathbf{C}\right]}\end{array}$ & $\begin{array}{c}\boldsymbol{T}_{\mathbf{m}} \\
{\left[{ }^{\circ} \mathbf{C}\right]}\end{array}$ & $\begin{array}{c}\text { Crystallinity } \\
{[\%]}\end{array}$ \\
\hline $\mathrm{PU}_{\text {PEG }}$ & -39 & - & - \\
\hline $\mathrm{PU}_{0.3}$ & -40 & - & - \\
\hline $\mathrm{PU}_{0.8}$ & -39 & - & - \\
\hline $\mathrm{PU}_{1.8}$ & -39 & - & - \\
\hline $\mathrm{PU}_{3.0}$ & -41 & 52.9 & 11 \\
\hline $\mathrm{PU}_{6.7}$ & -41 & 60.4 & 19 \\
\hline $\mathrm{PU}_{\mathrm{PCL}}$ & -41 & 57.7 & 25 \\
\hline
\end{tabular}

from the first heating are reported in Figure 7. Composition with a PCL/PEG ratio up to 1.8 showed only single glass transition near $-39^{\circ} \mathrm{C}$ suggesting amorphous one phase materials. An endothermic melting peak of crystalline PCL domains appeared with higher amounts of PCL. It was found that increasing the amount of PCL increases the bio-PU crystallinity up to $25 \%$ in the $\mathrm{PU}_{\mathrm{PCL}}$. The thermograph of neat PCL shows quite broad endothermic peak suggesting that PCL cannot crystallize in its neat form due to its low molecular weight.

$\mathrm{X}$-ray diffraction (WAXS) revealed the structure of the crystalline domains in the bio-PUs (Figure 8). Comparing the WAXS spectra of neat PCL polymer $\left(M_{\mathrm{n}}=80000 \mathrm{~g} \cdot \mathrm{mol}^{-1}\right)$ exhibiting two peaks at 21.4 and $23.8^{\circ}$ with the high PCL content bio-PUs, fair agreement with known PCL crystalline diffractions was found [24]. The increased width of the bio-PU $\mathrm{X}$-ray peaks and lower intensity can be ascribed to their less perfectly developed crystalline order. The size of crystallites was ranging between $2-9 \mathrm{~nm}$ according to line broadening at half the maximum intensity of diffraction peaks. According to the

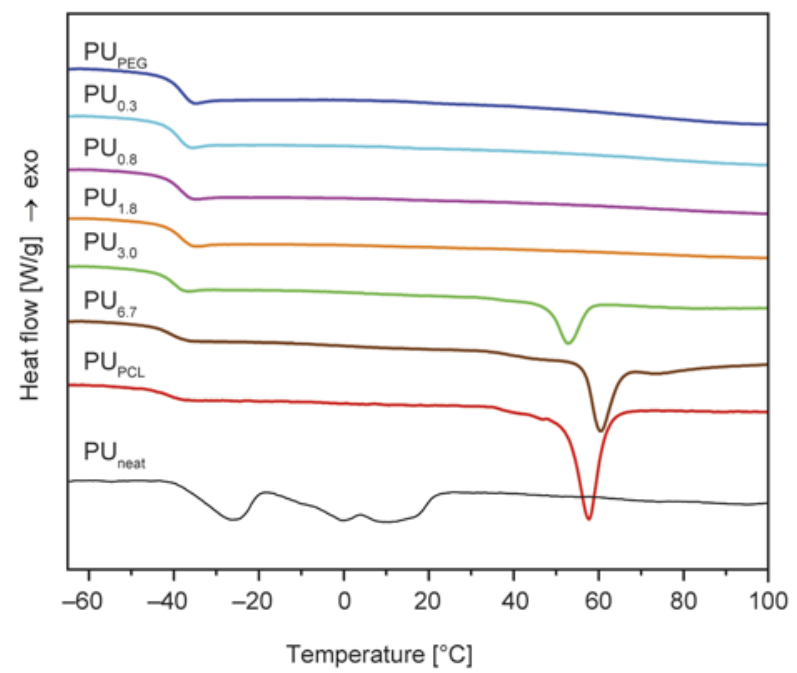

Figure 7. First heating endotherms of the prepared bio-PU samples obtained by DSC analysis

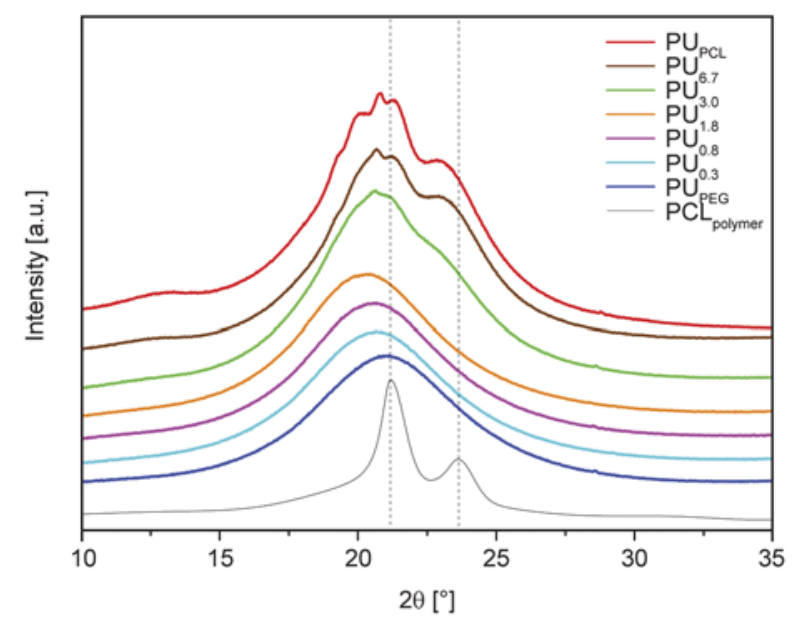

Figure 8. WAXS spectra of the prepared bio-PU specimens confirming crystalline domains of PCL at 20.8 and $22.7^{\circ}$ in $\mathrm{PU}_{3.0}, \mathrm{PU}_{6.7}$ and $\mathrm{PU}_{\mathrm{PCL}}$ samples. Other samples did not show any diffraction peaks.

Bragg's law, the small bands shift between the neat PCL polymer and $P U_{P C L}$ means an increase of interplanar space of PCL crystalline domains formed in bio-PUs. Their structure is influenced by polyurethane network resulting in longer distances between ordered PCL units confirmed by shift of the diffraction peaks to the lower $2 \theta$ values. The molecular weight of the used PCL macrodiol was low $\left(M_{\mathrm{n}}=\right.$ $530 \mathrm{~g} \cdot \mathrm{mol}^{-1}$ ), which accounts for approximately 4 $\varepsilon$-caprolactone monomeric units between the urethane groups. Despite the use of such short PCL chains, crystalline domains in the bio-PU samples were confirmed by both, DSC and WAXS analysis. Bio-PU films made up to molar excess of PCL to PEG equal to 1.8 showed broad amorphous halo without any diffraction peaks indicating no presence of crystalline phase in such films.

Extractions of the prepared bio-PU films were performed using dimethylformamide (DMF) to prove their crosslinked nature and employing acetone to determine the chemical composition of extracted residues (Figure 9). Extraction in DMF has not shown clear composition dependence of the extracted mass. The fact that the prepared bio-PUs did not dissolve in DMF was taken as an indirect evidence of their crosslinked nature influenced by both the excess of isocyanate in the feedstock mixture $(\mathrm{NCO} / \mathrm{OH}=1.2)$ and heat post cure. When taking into account possible reactions of isocyanate with other groups forming crosslinks in the system, the only one that can occur in anhydrous conditions is the reaction between isocyanate and urethane group forming allophanate crosslinks. However, allophanates cannot be easily 


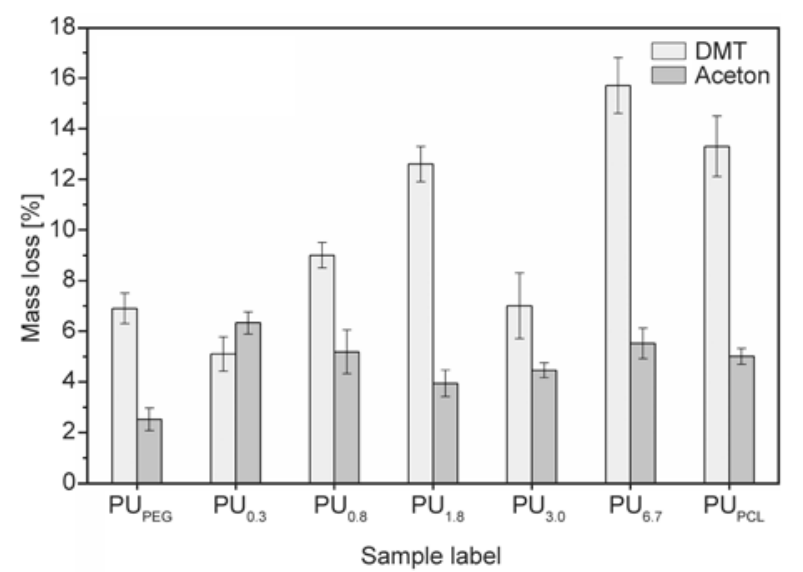

Figure 9. Results of the mass loss after extraction of bio-PU films

distinguished in infrared spectra due to the overlapping of the $\mathrm{C}=\mathrm{O}$ carbonyl group with the other one from the urethane group.

The comparison between infrared spectra of acetone extracted residues from bio-PU films with those recorded before extraction and with neat PEG and PCL are shown in Figure 10 and 11. All ATRIR spectra showed that linear, non-crosslinked bioPUs are presented in extracted residues. Comparison between PUPEG film and its extracted residue showed urethane groups represented by presence of $\mathrm{C}=\mathrm{O}$ band at around $1715 \mathrm{~cm}^{-1}$ and secondary amine band at $1536 \mathrm{~cm}^{-1}$ in the extracted residue. Broad $-\mathrm{OH}$ peak in the extracted residue suggest possible presence of free PEG diol. Similar results were obtained for the $\mathrm{PU}_{\mathrm{PCL}}$ when compared with its extracted residue and neat PCL. The presence of the urethane group was also confirmed by second-

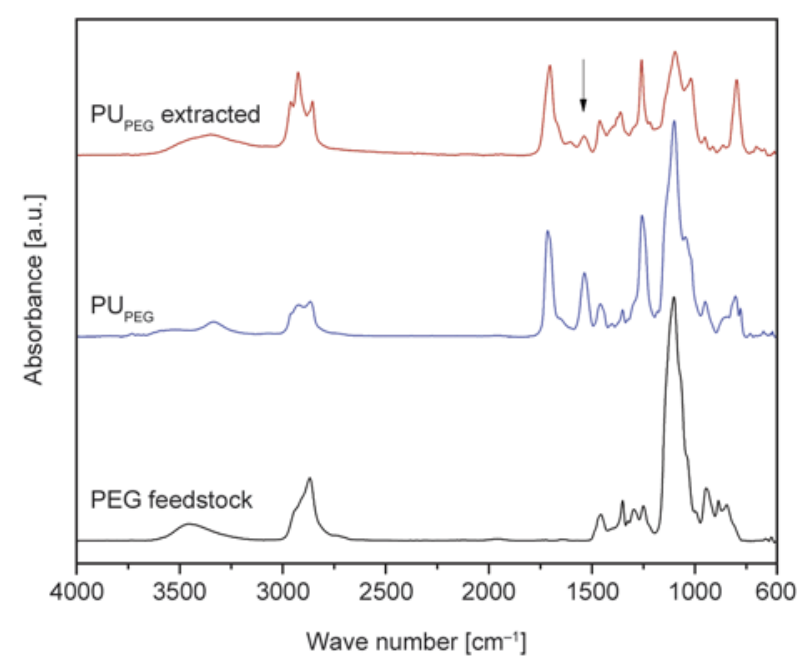

Figure 10. Comparison of $P U_{P E G}$ film ATR-IR spectra with its extracted residue and PEG feedstock. Presence of secondary amine band in extracted residue is emphasized by arrow.

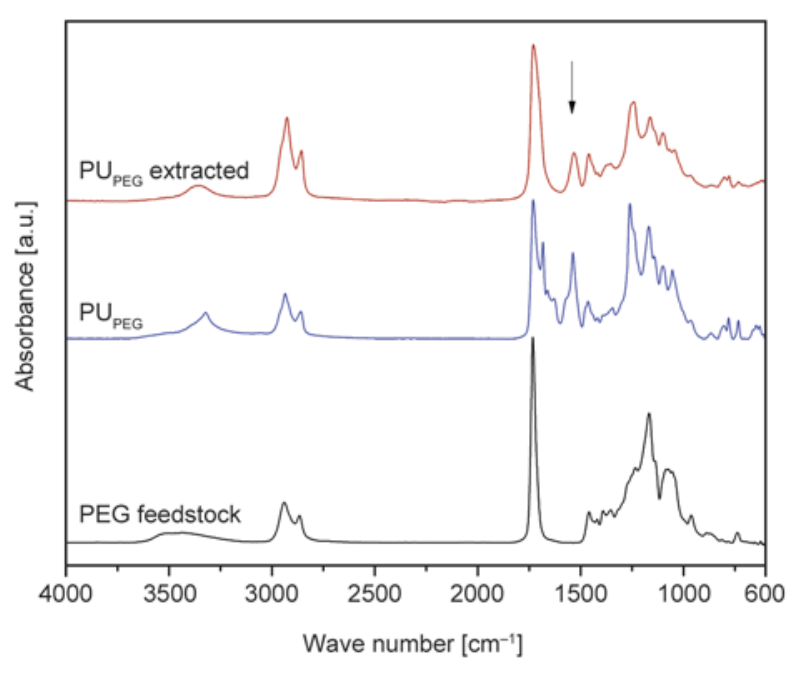

Figure 11. Comparison of $\mathrm{PU}_{\mathrm{PCL}}$ film ATR-IR spectra with its extracted residue and PCL feedstock. Presence of secondary amine band in extracted residue is emphasized by arrow.

ary amine band at $1536 \mathrm{~cm}^{-1}$. Additionally, the spectrum of extracted residue missed the band between $1690-1674 \mathrm{~cm}^{-1}$ attributed to hydrogen bonded carbonyl oxygen visible in $\mathrm{PU}_{\mathrm{PCL}}$ sample. None of the spectra showed strong isocyanate bands at 2360 and $2270 \mathrm{~cm}^{-1}$ confirming that unreacted HDI is not presented in any of the bio-PU materials.

\subsection{Swelling and hydrolytic degradation}

Results of swelling experiments in terms of the time dependence of the water uptake are shown in Figure 12. The standard deviation varied depending on PCL/PEG ratio in the range from $0.1 \%$ for $\mathrm{PU}_{\mathrm{PCL}}$ up to $6.3 \%$ for $\mathrm{PU}_{\mathrm{PEG}}$. PCL/PEG ratio strongly influences the ability to absorb water. As expected, hydro-

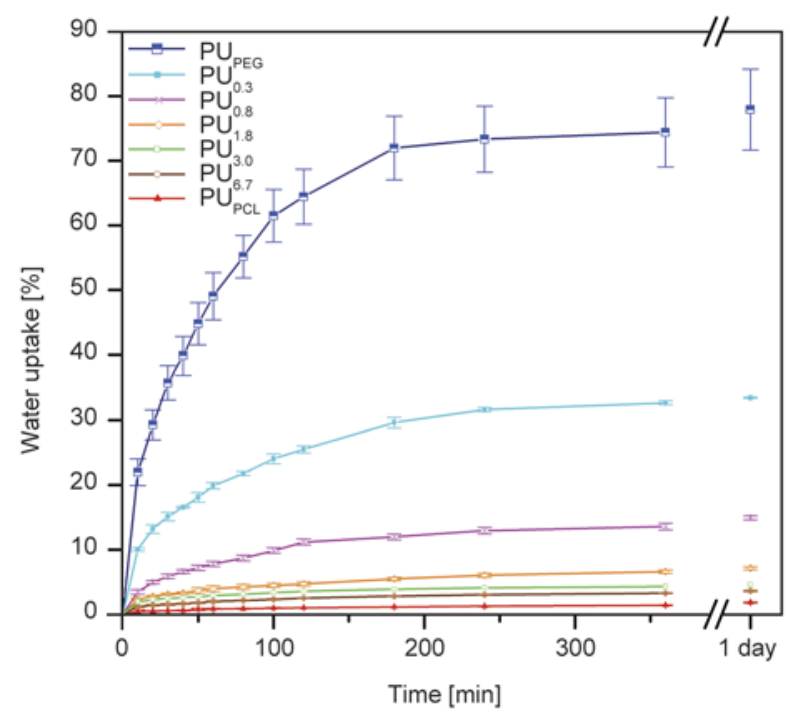

Figure 12. Swelling properties of the synthesized bio-PU films made with different PEG/PCL ratio 
philic $\mathrm{PU}_{\mathrm{PEG}}$ films showed the highest water uptake of $85.2 \pm 0.4 \%$ after one day of swelling. Water uptake decreased with decreasing amount of PEG diol. The hydrophobic $\mathrm{PU}_{\mathrm{PCL}}$ film exhibited the lowest water uptake of only $1.8 \pm 0.1 \%$ after one day swelling. The hydrophilic behavior of PEG is affected by the ether group repeating every 2 carbons in the macrodiol's chain compared with the hydrophobic PCL where five consecutive $-\mathrm{CH}_{2}-$ groups in the main chain contribute further to PCL hydrophobicity [25]. Moreover, the crystalline domains of PCL exhibit substantially smaller diffusion coefficient, hence, the kinetics of water uptake is massively slowed down.

In vitro hydrolytic degradation tests of the prepared bio-PU films were performed at $37^{\circ} \mathrm{C}$ in UPW. The time dependence of the mass loss is presented in Figure 13. The standard deviation increased for all the samples with time of degradation. The values depend on the $\mathrm{PCL} / \mathrm{PEG}$ ratio ranging for $\mathrm{PU} \mathrm{PEG}_{\mathrm{P}}$ sample from $0.36 \%$ (beginning) up to $18.2 \%$ (sample almost degraded) and for PUPCL from $0.13 \%$ (beginning) until $0.32 \%$ (end of the observation). The $\mathrm{PU}_{\mathrm{PEG}}$ film containing only $\mathrm{PEG}$ diol exhibited the fastest degradation rate since the sample completely decomposed in 23 weeks. Other compositions containing PCL did not show complete decomposition even over a period of one year. The expected bonds that undergo hydrolysis are ester and urethane ones, where esters are expected to be most unstable [16, 26]. Sample $P U_{P E G}$ contained from the two mentioned only urethane ones and those are expected to be hydrolyzed yielding shorter PU chains. Other reason might be gradual solubilization of $\mathrm{PU}_{\mathrm{PEG}}$ in water. Therefore, water uptake is an important parameter affecting the hydrolytic stability. Increase of

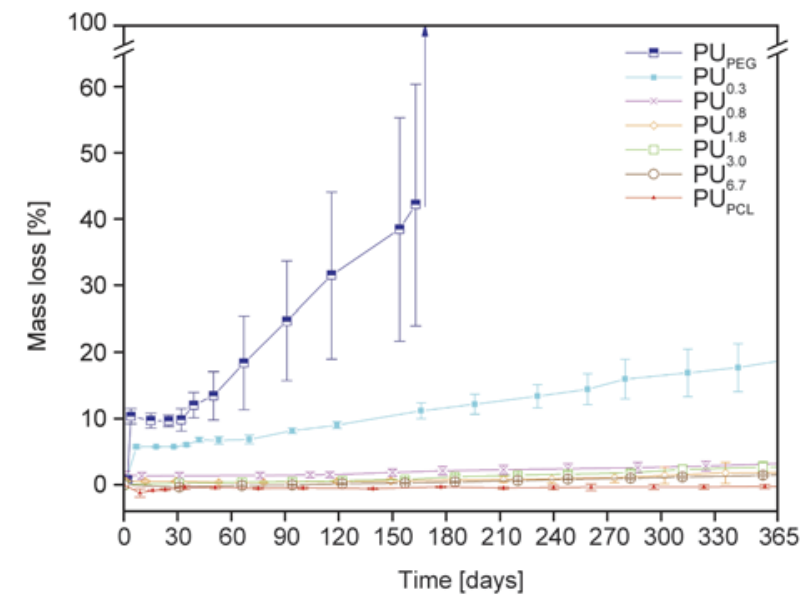

Figure 13. Hydrolytic degradation of the bio-PU films in the period of 1 year the PEG content in the PU enhanced the rate of the degradation. Hydrophobic nature of samples with higher presence of PCL prevented penetration of water into the material resulted in hydrolytically stable materials over the period of one year.

\subsection{Thermal stability}

The rate of thermal degradation plotted against temperature is shown in Figure 14. The first weight reduction at approximately $125^{\circ} \mathrm{C}$ was caused by removing adsorbed water from the bio-PU surface. The first weight loss was proportional to the amount of PEG in the bio-PU film due to its hydrophilic nature. The thermal degradation subsequently proceeded in two major steps.

More than $80 \%$ weight of all the prepared compositions was lost in the temperature interval between 270 and $380^{\circ} \mathrm{C}$. Temperature dependence of the rate of weight loss shows some evidence for presence of several thermal degradation processes. One can assume decomposition of urethane and ester groups with the maximum rate between $310-325^{\circ} \mathrm{C}$ and decomposition of ether bonds at higher temperatures with maximum rate between $325-350^{\circ} \mathrm{C}[27,28]$. The urethane bonds decompose into alcohols and isocyanates, while the decomposition of ester and ether bonds in PCL and PEG, respectively, is assumed through chain scission [29]. The second step occurring between $410-470{ }^{\circ} \mathrm{C}$ is assigned to the $\mathrm{C}-\mathrm{C}$ bond cleavage.

\subsection{Mechanical properties analysis}

Stress-strain curves of the prepared bio-PU compositions are shown in Figure 15. Samples having the PCL/PEG ratio below 1.8 exhibited brittle deforma-

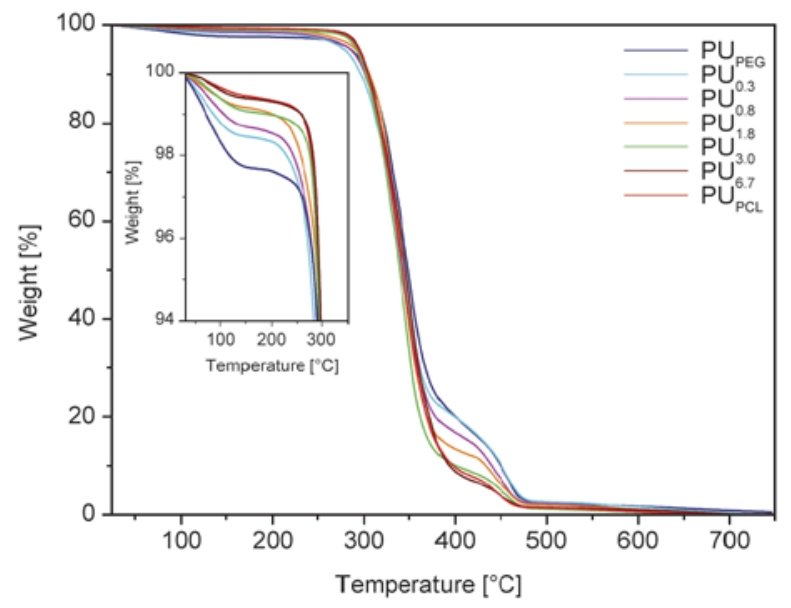

Figure 14. Thermal stability of the bio-PU samples 


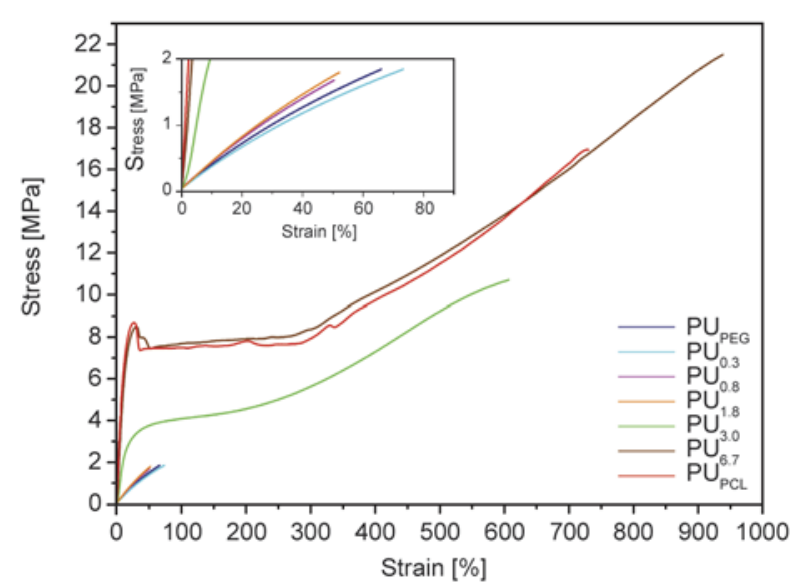

Figure 15. Stress-strain curves of bio-PU films showing rapid change in mechanical properties for PCL/ PEG ratio $\geq 3$

tion behavior (inset in Figure 15). As the PCL/PEG ratio increased above 2 , the mechanical response abruptly changed increasing the elastic modulus, stress and deformation at break by order of magnitude while not exhibiting post-yield strain softening. Considerable post-yield strain softening was observed for samples with PCL/PEG ratio above 6 (Figure 15). Young's modulus $\left(E_{\mathrm{y}}\right)$, tensile stress at break $\left(\sigma_{\mathrm{B}}\right)$, tensile strain at break $\left(\varepsilon_{\mathrm{B}}\right)$, and the yield point $\left(\sigma_{\mathrm{y}}\right)$ are listed in Table 3. Mechanical properties are profoundly affected by the increasing amount of PCL in the diol mixture.

Plausible explanation of such mechanical behavior is based on spider dragline model introduced by Termonia [30]. Model ascribes high tensile strength and ductility of spider dragline to the presence of very small crystals $(2 \times 6 \times 21 \mathrm{~nm})$ in the rubbery matrix. In agreement with WAXS evidence the bio-PUs with PCL/PEG $\geq 3$ are assumed as a semicrystalline material containing a large number of small crystallites dispersed in amorphous regions made of rubber-like chains. The size of crystallites ranges between $2-$ $9 \mathrm{~nm}$ according to line broadening at half the maximum intensity of diffraction peaks. This explanation

Table 3. Mechanical properties of the prepared bio-PU films calculated from stress-strain curves

\begin{tabular}{|l|c|c|c|c|}
\hline $\begin{array}{c}\text { Label of } \\
\text { sample }\end{array}$ & $\begin{array}{c}\boldsymbol{E}_{\mathbf{y}} \\
{[\mathbf{M P a}]}\end{array}$ & $\begin{array}{c}\boldsymbol{\sigma}_{\mathbf{y}} \\
{[\mathbf{M P a}]}\end{array}$ & $\begin{array}{c}\boldsymbol{\sigma}_{\mathbf{B}} \\
{[\mathbf{M P a}]}\end{array}$ & $\begin{array}{c}\boldsymbol{\varepsilon}_{\mathbf{B}} \\
{[\mathbf{\%}]}\end{array}$ \\
\hline $\mathrm{PU}_{\mathrm{PEG}}$ & $3.6 \pm 0.2$ & - & $1.9 \pm 0.2$ & $70 \pm 11$ \\
\hline $\mathrm{PU}_{0.3}$ & $3.5 \pm 0.3$ & - & $1.7 \pm 0.2$ & $64 \pm 12$ \\
\hline $\mathrm{PU}_{0.8}$ & $4.2 \pm 0.1$ & - & $1.7 \pm 0.2$ & $50 \pm 8$ \\
\hline $\mathrm{PU}_{1.8}$ & $4.0 \pm 0.1$ & - & $1.7 \pm 0.2$ & $50 \pm 8$ \\
\hline $\mathrm{PU}_{3.0}$ & $27.1 \pm 2.4$ & - & $10.7 \pm 1.2$ & $600 \pm 103$ \\
\hline $\mathrm{PU}_{6.7}$ & $67.8 \pm 3.0$ & $8.5 \pm 0.3$ & $21.5 \pm 1.4$ & $947 \pm 48$ \\
\hline $\mathrm{PU}_{\mathrm{PCL}}$ & $80.1 \pm 3.8$ & $8.9 \pm 0.5$ & $18.1 \pm 1.7$ & $830 \pm 100$ \\
\hline
\end{tabular}

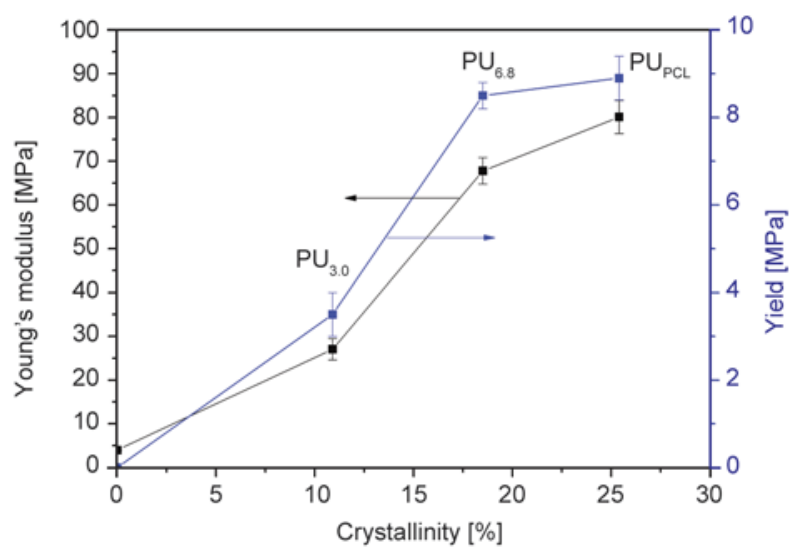

Figure 16. Correlation between mechanical properties (Young's modulus, yield point) plotted against crystallinity

Table 4. Mechanical properties of some human soft tissues [12]

\begin{tabular}{|l|c|c|}
\hline \multicolumn{1}{|c|}{ Tissue } & $\begin{array}{c}\text { Young's modulus } \\
{[\mathbf{M P a}]}\end{array}$ & $\begin{array}{c}\text { Strain at break } \\
{[\mathbf{\%}]}\end{array}$ \\
\hline Relaxed smooth muscle & 0.006 & 300 \\
\hline Contracted smooth muscle & 0.01 & 300 \\
\hline Myocardium [31] & $0.2-0.5$ & $20<90$ \\
\hline Cerebral vein & 6.85 & 83 \\
\hline Aortic valve leaflet & $15 \pm 6$ & $21 \pm 12$ \\
\hline Pericardium & $20.4 \pm 1.9$ & $34.9 \pm 1.1$ \\
\hline $\mathrm{PU}_{3.0}$ & $27.1 \pm 2.4$ & $600 \pm 103$ \\
\hline
\end{tabular}

is supported by correlation between mechanical properties (Young's modulus, yield point) plotted against crystallinity in Figure 16. Thus, the abrupt change of deformation response is explained by the formation of small crystalline domains of PCL.

The amount of PCL feedstock in the material is strongly influencing mechanical properties. This could be further utilized for the preparation of an elastic resorbable material useful in the human body, e.g. as an artificial vascular grafts or as a material against post-surgical adhesions. Short summary of mechanical properties of some human soft tissues is reported in Table 4. Selecting from the prepared bioPU films the sample labeled as $\mathrm{PU}_{3.0}$ did not show sharp yield point determining its very good elastic properties. In addition the sample is quite tough with elongation of about $600 \%$ which is favorable for safe manipulation with the material during surgical operation.

\subsection{Morphology and surface properties}

Bio-PU films morphology was affected by the roughness of the mold, most likely due to processing in bulk. Confocal microscopy images showed similar surface texture of prepared samples and calculated 
Table 5. Water contact angles of bio-PU films

\begin{tabular}{|c|c|}
\hline Sample label & $\begin{array}{c}\text { Contact angle } \\
{\left[{ }^{\circ}\right]}\end{array}$ \\
\hline $\mathrm{PU}_{\mathrm{PEG}}$ & $61.8 \pm 3.4$ \\
\hline $\mathrm{PU}_{0.3}$ & $72.3 \pm 3.7$ \\
\hline $\mathrm{PU}_{0.8}$ & $77.1 \pm 3.0$ \\
\hline $\mathrm{PU}_{1.8}$ & $82.5 \pm 2.6$ \\
\hline $\mathrm{PU}_{3.0}$ & $84.0 \pm 1.3$ \\
\hline $\mathrm{PU}_{6.7}$ & $87.8 \pm 0.9$ \\
\hline $\mathrm{PU}_{\mathrm{PCL}}$ & $88.6 \pm 1.1$ \\
\hline
\end{tabular}

roughness average $\left(R_{\mathrm{a}}\right)$ showed fair agreement between the Teflon ${ }^{\circledR}$ mold $\left(R_{\mathrm{a}}=0.48 \pm 0.12 \mu \mathrm{m}\right)$ as well as on the surfaces of $\mathrm{PU}_{\mathrm{PEG}}\left(R_{\mathrm{a}}=0,67 \pm 0.35 \mu \mathrm{m}\right)$ and PUPCL samples $\left(R_{\mathrm{a}}=0.55 \pm 0.28 \mu \mathrm{m}\right)$. The roughness of the films can be advantageously tuned by roughness of the mold meeting different medical applications.

Macroscopic measurements of wettability depicted in Table 5 illustrated an increase in contact angle of around $30^{\circ}$ from hydrophilic $\mathrm{PU}_{\mathrm{PEG}}$ to hydrophobic $\mathrm{PU}_{\mathrm{PCL}}$ sample. The resulting trend corresponds well with the data obtained by swelling where weight ratio between PCL and PEG influences the ability of the material to absorb water.

\section{Cell viability evaluation}

From all the synthesized samples three of them were chosen for preliminary tests on human mesenchymal stem cells (MSCs) response to the material. Chosen samples were bio-PUs made of only macrodiol (PEG or PCL) and isocyanate (samples $\mathrm{PU}_{\mathrm{PEG}}$ and $\mathrm{PU}_{\mathrm{PCL}}$ ) and sample $\mathrm{PU}_{3.0}$ due to its promising mechanical properties. Analysis of cell viability was performed to determine qualitative changes in cellular growth which involve cell adhesion and proliferation observed by confocal fluorescent microscopy. Cell viability tests were conducted by incubating MSCs on the sample over 24, 72 and 168 hours at $37^{\circ} \mathrm{C}$. Adhered cells were observed only on the samples $\mathrm{PU}_{3.0}$ and $\mathrm{PU}_{\mathrm{PCL}}$ (Figure 17a and 17b, respectively) after 24 hours. No MSCs have been seen on PUPEG sample after 24 hours. This phenomenon is most likely because the PEG based PUs provide a non-adherent environment for MSCs which then undergo apparently no adhesion (PU $\mathrm{PEG}_{\mathrm{PE}}$ ) or fast detachment $\left(\mathrm{PU}_{3.0)}\right.$ from PEGylated surface. By contrast, $\mathrm{PU}_{\mathrm{PCL}}$ sample provided better substrate for MSCs which supported good adhesion of some MSCs. The cells attached to this bio-PU surface showed flat, well spread morphology over 48 hours
(Figure 17c). Only a few surviving cells were observed on $\mathrm{PU}_{\mathrm{PCL}}$ sample after the period of one week (Figure 17d).

Parameters that can change the biological activity of materials are related to physico-chemical properties of the material surface, such as surface chemistry, wettability, micro-roughness and especially in the case of biodegradable materials their degradation compounds.

Both materials that demonstrated cell adhesion were stable during performed degradation tests in UPW, nevertheless, they might release some uncrosslinked molecules. No cell adhesion on $\mathrm{PU}_{\mathrm{PEG}}$ and the low adhesion without evident proliferation on $\mathrm{PU}_{3.0}$ and $\mathrm{PU}_{\mathrm{PCL}}$ could be partly attributed to the morphology of polymer surface promoting inhibition of the cell growth. Other reason might be the presence of remaining tin(II) 2-ethylhexanoate catalyst in the material due to the synthesis procedure carried out in bulk. Although the catalyst is FDA approved, this disadvantage has to be overcome by different synthesis procedure of bio-PU, e.g. synthesis at higher temperature without the need of catalyst and still without the need of solvent. Our preliminary results with MSCs did not provide complete information about the cell behavior on selected materials, therefore more in vitro analysis of cell viability will be performed as well as various cells must be tested. Observed low MSC's adherence is favorable parameter for the potential use of the material as an artificial vein. However for interaction with a body, further modification of the contact side is desirable by compounds favoring cell adhesion e.g. by RGD proteins.

\section{Conclusions}

Biodegradable PU films with variable PCL/PEG diol ratio were synthesized without the need of a solvent. The experimental study revealed that addition of PCL strongly affects mechanical properties of bio-PU films, especially for PCL/PEG ratio higher than 1.8. In comparison to PU containing only PEG $\left(\mathrm{PU}_{\mathrm{PEG}}\right)$, the Young's modulus, tensile stress and strain at break increased by 1-2 orders of magnitude. WAXS and DSC measurements revealed formation of crystalline PCL domains at PCL/PEG ratio above 1.8. These domains reinforce the PU network and their small size allows for more uniform distribution of strain resulting in enhanced ductility. The ability to absorb water and the rate of hydrolytic 


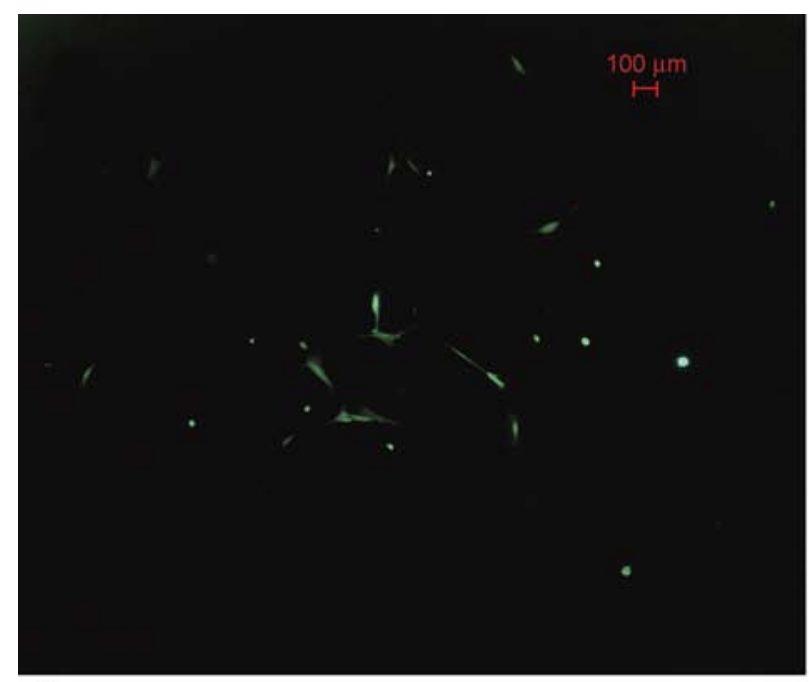

a)

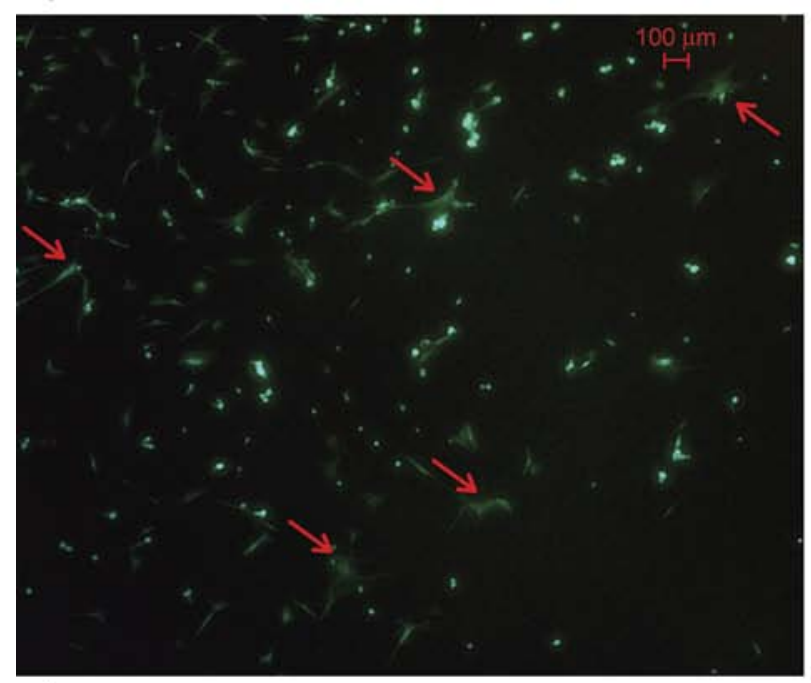

c)

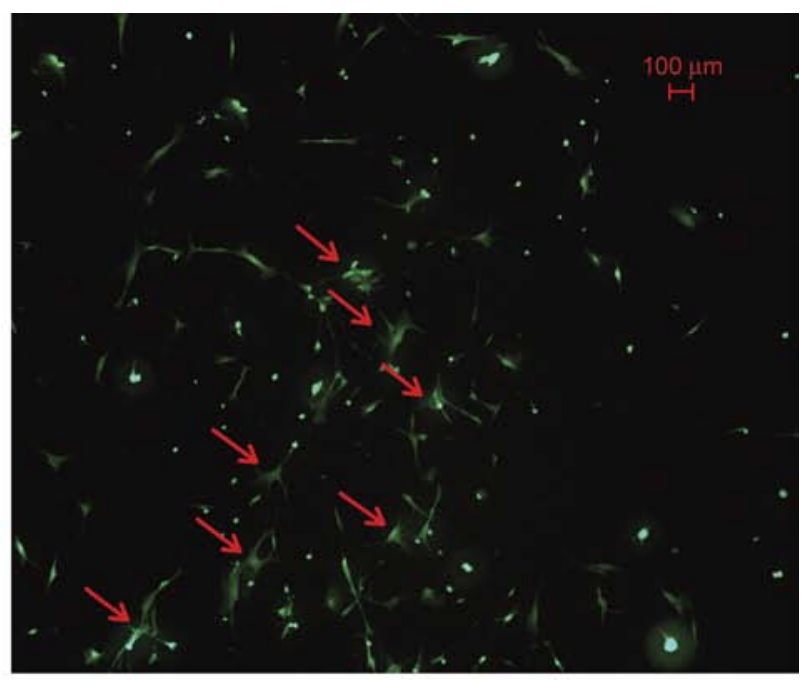

b)

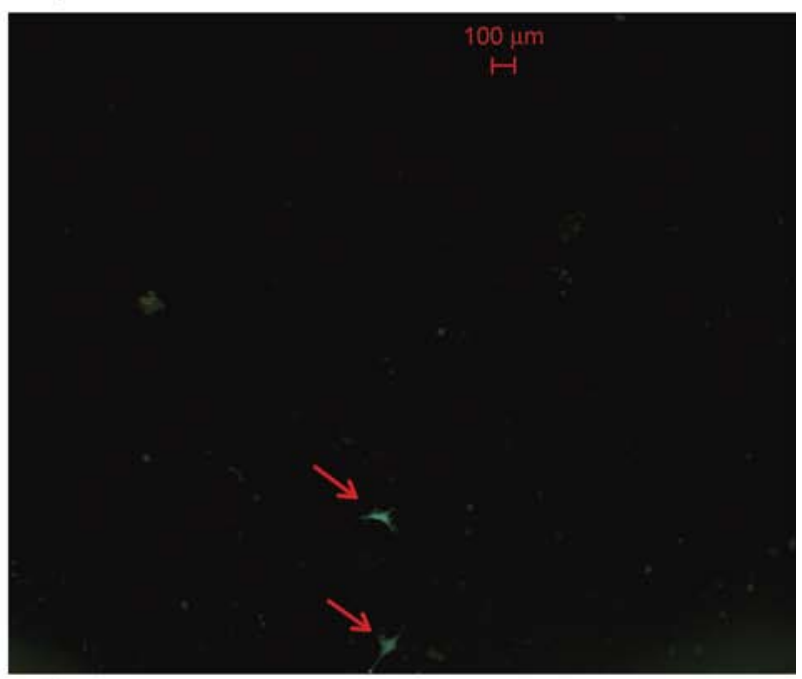

d)

Figure 17. Live/dead assay after seeding with MSCs of sample a) $P_{3.0}$ after 24 hours, b) $\mathrm{PU}_{\mathrm{PCL}}$ after 24 hours, c) PUPCL

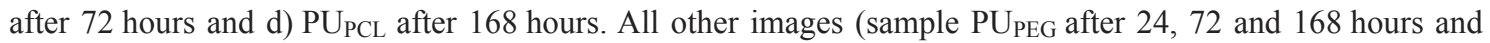
$\mathrm{PU}_{3.0}$ after 72 and 168 hours) were black without any sign of adhered cells on the surface.

degradation both increased with increasing amount of hydrophilic PEG in the compositions. This study demonstrated that by changing the ratio between hydrophilic and hydrophobic macrodiols physicochemical properties of biodegradable bio-PUs can be tailored. Bio-PU material could be utilized for the preparation of elastic resorbable materials applicable as non-adherent surface against post-surgical adhesions.

\section{Acknowledgements}

This research has been financially supported by the Ministry of Education, Youth and Sports of the Czech Republic under the project CEITEC 2020 (LQ1601). The authors are also thankful to Josef Skopalik and Ivan Justan (The International Clinical Research Center of St. Anne's University Hospital in Brno, Czech Republic) for providing MSCs.

\section{References}

[1] Howard G. T.: Biodegradation of polyurethane: A review. International Biodeterioration and Biodegradation, 49, 245-252 (2002).

DOI: $10.1016 / \mathrm{S} 0964-8305(02) 00051-3$

[2] Santerre J., Woodhouse K. A., Laroche G., Labow R.: Understanding the biodegradation of polyurethanes: From classical implants to tissue engineering materials. Biomaterials, 26, 7457-7470 (2005). DOI: $10.1016 /$ j.biomaterials.2005.05.079

[3] Guelcher S. A.: Biodegradable polyurethanes: Synthesis and applications in regenerative medicine. Tissue Engineering Part B: Reviews, 14, 3-17 (2008). DOI: 10.1089/teb.2007.0133

[4] Sartori S., Chiono V., Tonda-Turo C., Mattu C., Gianluca $\mathrm{C}$. : Biomimetic polyurethanes in nano and regenerative medicine. Journal of Materials Chemistry B, 2, 5128-5144 (2014).

DOI: $10.1039 / \mathrm{C} 4 \mathrm{~TB} 00525 \mathrm{~B}$ 
[5] Vermette P., Griesse H. J., Laroche G., Guidoin R.: Developments in design and synthesis of biostable polyurethanes. in 'Biomedical applications of polyurethanes' (eds.: Gunatillake P. A., Meijs G. F., McCarthy S. J.) Landes Bioscience, Georgetown, 160-170 (2001).

[6] Ratcliffe A.: Tissue engineering of vascular grafts. Matrix Biology, 19, 353-357 (2000).

DOI: $10.1016 /$ S0945-053X(00)00080-9

[7] Grad S., Kupcsik L., Gorna K., Gogolewski S., Alini M.: The use of biodegradable polyurethane scaffolds for cartilage tissue engineering: Potential and limitations. Biomaterials, 24, 5163-5171 (2003).

DOI: $10.1016 / \mathrm{S} 0142-9612(03) 00462-9$

[8] Gogolewski S., Gorna K.: Biodegradable polyurethane cancellous bone graft substitutes in the treatment of iliac crest defects. Journal of Biomedical Materials Research Part A, 80, 94-101 (2007).

DOI: $10.1002 / \mathrm{jbm} . \mathrm{a} .30834$

[9] Bergmeister H., Seyidova N., Schreiber C., Strobl M., Grasl C., Walter I., Messner B., Baudis S., Fröhlich S., Marchetti-Deschmann M., Griesser M., di Franco M., Krssak M., Liska R., Schima H.: Biodegradable, thermoplastic polyurethane grafts for small diameter vascular replacements. Acta Biomaterialia, 11, 104-113 (2015).

DOI: $10.1016 /$ j.actbio.2014.09.003

[10] Penco M., Sartore L., Bignotti F., D’Antone S., Di Landro L.: Thermal properties of a new class of block copolymers based on segments of poly(D,L-lactic-glycolic acid) and poly( $\varepsilon$-caprolactone). European Polymer Journal, 36, 901-908 (2000).

DOI: $\underline{10.1016 / \mathrm{S} 0014-3057(99) 00155-\mathrm{X}}$

[11] Martin D. J., Meijs G. F., Gunatillake P. A., Yozghatlian S. P., Renwick G. M.: The influence of composition ratio on the morphology of biomedical polyurethanes. Journal of Applied Polymer Science, 71, 937-952 (1999). DOI: $10.1002 /($ SICI $) 1097-4628(19990207) 71: 6<937::$ AID-APP9>3.0.CO;2-0

[12] Chen Q., Liang S., Thouas G. A.: Elastomeric biomaterials for tissue engineering. Progress in Polymer Science, 38, 584-671 (2013).

DOI: $10.1016 /$ j.progpolymsci.2012.05.003

[13] Kim H-J., Kang M-S., Knowles J-C., Gong M-S.: Synthesis of highly elastic biocompatible polyurethanes based on bio-based isosorbide and poly(tetramethylene glycol) and their properties. Journal of Biomaterials Applications, 29, 454-464 (2014). DOI: $10.1177 / 0885328214533737$

[14] Hassan M., Mauritz K., Storey R., Wiggins J.: Biodegradable aliphatic thermoplastic polyurethane based on poly( $\varepsilon$-caprolactone) and L-lysine diisocyanate. Journal of Polymer Science Part A: Polymer Chemistry, 44, 2990-3000 (2006). DOI: $10.1002 /$ pola.21373
[15] Cometa S., Bartolozzi I., Corti A., Chiellini F., De Giglio E., Chiellini E.: Hydrolytic and microbial degradation of multi-block polyurethanes based on poly( $\varepsilon$ caprolactone)/poly(ethylene glycol) segments. Polymer Degradation and Stability, 95, 2013-2021 (2010). DOI: 10.1016/j.polymdegradstab.2010.07.007

[16] Mondal S., Martin D.: Hydrolytic degradation of segmented polyurethane copolymers for biomedical applications. Polymer Degradation and Stability, 97, 15531561 (2012). DOI: 10.1016/j.polymdegradstab.2012.04.008

[17] Sartori S., Boffito M., Serafini P., Caporale A., Silvestri A., Bernardi E., Sassi M. P., Boccafoschi F., Ciardelli G.: Synthesis and structure-property relationship of polyester-urethanes and their evaluation for the regeneration of contractile tissues. Reactive and Functional Polymers, 73, 1366-1376 (2013). DOI: $10.1016 /$ j.reactfunctpolym.2013.01.006

[18] Chan-Chan L., Solis-Correa R., Vargas-Coronado R., Cervantes-Uc J., Cauich-Rodríguez J., Quintana P., Bartolo-Pérez P.: Degradation studies on segmented polyurethanes prepared with HMDI, PCL and different chain extenders. Acta Biomaterialia, 6, 2035-2044 (2010). DOI: $10.1016 /$ j.actbio.2009.12.010

[19] Li G., Li D., Niu Y., He T., Chen K. C., Xu K.: Alternating block polyurethanes based on PCL and PEG as potential nerve regeneration materials. Journal of Biomedical Materials Research Part A, 102, 685-697 (2014).

DOI: $10.1002 / \mathrm{jbm} \cdot \mathrm{a} .34732$

[20] Silvestri A., Sartori S., Boffito M., Mattu C., di Rienzo A. M., Boccafoschi F., Ciardelli G.: Biomimetic myocardial patches fabricated with poly( $\varepsilon$-caprolactone) and polyethylene glycol-based polyurethanes. Journal of Biomedical Materials Research Part B: Applied Biomaterials, 102, 1002-1013 (2014).

DOI: $\underline{10.1002 / \mathrm{jbm} . b .33081}$

[21] Kweon H. Y., Yoo M. K., Park I. K., Kim T. H., Lee H. C., Lee H-S., Oh J-S., Akaike T., Cho C-S.: A novel degradable polycaprolactone networks for tissue engineering. Biomaterials, 24, 801-808 (2003). DOI: $10.1016 / \mathrm{S} 0142-9612(02) 00370-8$

[22] Rueda-Larraz L., d'Arlas B., Tercjak A., Ribes A., Mondragon I., Eceiza A.: Synthesis and microstructure-mechanical property relationships of segmented polyurethanes based on a PCL-PTHF-PCL block copolymer as soft segment. European Polymer Journal, 45, 2096-2109 (2009).

DOI: $10.1016 /$ j.eurpolymj.2009.03.013

[23] Pretsch T., Jakob I., Müller W.: Hydrolytic degradation and functional stability of a segmented shape memory poly(ester urethane). Polymer Degradation and Stability, 94, 61-73 (2009).

DOI: $10.1016 /$ j.polymdegradstab.2008.10.012 
[24] Correlo V. M., Boesel L. F., Bhattacharya M., Mano J. F., Neves N. M., Reis R. L.: Properties of melt processed chitosan and aliphatic polyester blends. Materials Science and Engineering: A, 403, 57-68 (2005).

DOI: $10.1016 / \mathrm{j} . \mathrm{msea} \cdot 2005.04 .055$

[25] Woodruff M. A., Hutmacher D. W.: The return of a forgotten polymer - Polycaprolactone in the $21^{\text {st }}$ century. Progress in Polymer Science, 35, 1217-1256 (2010). DOI: $10.1016 /$ j.progpolymsci.2010.04.002

[26] Schollenberger C. S., Stewart F. D.: Thermoplastic polyurethane hydrolysis stability. Journal of Elastomers and Plastics, 3, 28-56 (1971).

DOI: $10.1177 / 009524437100300103$

[27] Chattopadhyay D., Webster D.: Thermal stability and flame retardancy of polyurethanes. Progress in Polymer Science, 34, 1068-1133 (2009).

DOI: $10.1016 /$ j.progpolymsci.2009.06.002
[28] Król P.: Linear polyurethanes: Synthesis methods, chemical structures, properties and applications. VSP, Boston (2008).

[29] Kong X., Liu G., Curtis J.: Novel polyurethane produced from canola oil based poly(ether ester) polyols: Synthesis, characterization and properties. European Polymer Journal, 48, 2097-2106 (2012).

DOI: 10.1016/j.eurpolymj.2012.08.012

[30] Termonia Y.: Molecular modeling of spider silk elasticity. Macromolecules, 27, 7378-7381 (1994). DOI: $10.1021 / \mathrm{ma} 00103 \mathrm{a} 018$

[31] Boffito M., Sartori S., Ciardelli G.: Polymeric scaffolds for cardiac tissue engineering: Requirements and fabrication technologies. Polymer International, 63, 211 (2014).

DOI: $10.1002 /$ pi.4608 